\title{
A IMPORTÂNCIA DO CONHECIMENTO LOCAL DOS AGRICULTORES FAMILIARES E DEMAIS POPULAÇÕES RURAIS PARA 0 DESENVOLVIMENTO RURAL SUSTENTÁVEL
}

THE IMPORTANCE OF LOCAL KNOWLEDGE OF FAMILY FARMERS AND OTHER RURAL POPULATIONS FOR SUSTAINABLE RURAL DEVELOPMENT

\section{Odacir Miguel Tagliapietra}

Doutor em Desenvolvimento Rural Sustentável pela Universidade Estadual do Oeste do Paraná (Cascavel/Brasil).

Professor Adjunto A na Universidade Estadual do Oeste do Paraná (Marechal Cândido Rondon/Brasil).

E-mail: odacir.tagliapietra@unioeste.br

\section{Irene Carniatto}

Doutora em Ciências Florestais, Conservação e Planejamento Integrado de Bacias e de Recursos Hídricos pela Universidade Federal do Paraná (Curitiba/Brasil). Docente do Programa de Pós-graduação Mestrado e Doutorado em Desenvolvimento Rural Sustentável e Coordenadora do Centro de Ensino, Pesquisas e Extensão em Proteção e Desastre na Universidade Estadual do Oeste do Paraná (Marechal Cândido Rondon/Brasil).

E-mail: irenecarniatto@gmail.com

\section{Geysler Bertolini}

Doutor em Engenharia de Produção pela Universidade Federal de Santa Catarina (Florianópolis/Brasil).

Pró-Reitor de Administração e Finanças na Universidade Estadual do Oeste do Paraná (Marechal Cândido Rondon/Brasil).

E-mail: geysler.bertolini@unioeste.br 


\section{RESUMO}

Na sociedade do conhecimento, as pessoas são de grande importância para as organizações, pois são elas que possuem conhecimentos, muitas vezes tácitos, essenciais para o desenvolvimento de estratégias que visam ao aumento da competitividade e da produtividade. A busca pela valorização dos diversos saberes está se tornando cada vez mais uma dinâmica em todas as áreas do conhecimento. O processo de modernização da agricultura interferiu no modo de produção dos agricultores que, a partir de uma visão reducionista, buscou homogeneizar a forma de produção, fundamentada nos conhecimentos técnico-científicos, desconsiderando-se os saberes tradicionais das comunidades rurais. Nos últimos anos, estudos têm demonstrado a necessidade de se adotar uma abordagem Inter e Transdisciplinar com a preocupação quanto ao desenvolvimento sustentável, envolvendo diversos tipos de saberes. Assim, o objetivo deste artigo foi analisar o processo da gestão do conhecimento local ou tradicional no contexto da agricultura familiar e demais populações rurais na perspectiva do desenvolvimento rural sustentável, a partir de uma revisão sistemática na literatura. As bases de dados utilizadas para busca foram: web of Science, Scopus, Capes e BDTD. Os resultados das buscas foram oriundos dos seguintes Continentes: Ásia Meridional, Sudeste Asiático, Europa Ocidental, América do Sul e Oceania. Os estudos demonstraram que, na literatura e no meio acadêmico, nos últimos anos, houve uma valorização dos conhecimentos local ou tradicional. No entanto, na prática, ainda são poucas as iniciativas que estimulam o diálogo entre os conhecimentos técnico-científicos e os conhecimentos tradicionais.

Palavras-chave: Gestão do Conhecimento. Agricultura Familiar. Desenvolvimento Rural Sustentável. Conhecimento Tradicional. Conhecimento Tácito.

\section{ABSTRACT}

Knowledge society points out that people are of great importance to organizations, since they are the ones who have knowledge, mostly considered tacit, and essential to develop strategies that aimed at increasing competitiveness and yield. So, searching for valuing diverse knowledge has become increasingly dynamic in all knowledge areas. The modernization process of agriculture intervened on how farmers' crop, which, based on a reductionist viewpoint, aimed at homogenizing yield decision-making, according to technical-scientific knowledge, disregarding the traditional knowledge from rural communities. During the last years, studies have shown the importance of adopting interdisciplinary and transdisciplinary approaches, with some concern on sustainable development, involving different kinds of knowledge. Thus, the study aims at analyzing the process of local or traditional knowledge management in family farming context and other rural populations in order to improve sustainable rural development, based on a systematic review of the literature. The databases used for this research were: web of Science, Scopus, Capes and BDTD. The search results came from the following continents: Meridional Asia, Southeastern Asia, Western Europe, Southern America and Oceania. The studies have shown that according to the literature and academic area, in recent years, there was some development on traditional knowledge. Therefore, in real life, there still have few measures that stimulate the dialogue among scientific-techniques and local or traditional knowledge.

Keywords: Knowledge Management. Family Farming. Sustainable Rural Development. Traditional Knowledge. Tacit Knowledge. 


\section{INTRODUÇÃO}

A valorização do conhecimento como um diferencial para alavancar o desenvolvimento de organizações e agregação de valor para produtos e serviços tem sido um fator de destaque nos estudos relacionados à necessidade de se buscar inovações e alternativas de desenvolvimento para as organizações e comunidades de maneira geral.

No contexto das atividades rurais, que é o foco deste estudo, a tentativa de disseminar as inovações tecnológicas tornou-se um processo discriminatório, pois, muitos costumes e práticas dos agricultores tradicionais foram negligenciados e considerados ultrapassados. Mas com o passar dos anos, tem-se verificado que o processo de homogeneização da agricultura como uma proposta de desenvolvimento trouxe enormes problemas socioambientais para os pequenos agricultores, também denominados de agricultores familiares.

Nesse sentido, a relevância desse trabalho está em apresentar estudos sobre essa problemática que demonstram a necessidade de se reverter o processo de negação dos conhecimentos tradicionais, tendo em vista que as populações que desenvolvem atividades resultantes de práticas transmitidas de geração para geração apresentam muitos conhecimentos, os quais se compartilhados com os conhecimentos técnico-científicos podem agregar valor aos produtos considerados tradicionais que apresentam diferenciais tácitos, tornando-se, desta maneira, um diferencial do produto ou serviço no mercado.

Na sociedade do conhecimento, as pessoas deixam de ser meros recursos de produção, semelhantes aos demais, tornando-se um ativo imprescindivel para a competitividade e a sobrevivência das organizações. Conforme Drucker (2002, p. 96), "em escala cada vez maior, o sucesso e, de fato, a sobrevivência de toda empresa irá depender do desempenho da sua força de trabalho de conhecimento".

De acordo com Nonaka e Takeuchi (1997), o conhecimento apresenta duas dimensões: tácita e explícita. O conhecimento tácito é difícil de ser transferido pelos métodos de ensino tradicionais, pois é subjetivo, pessoal e dependente das experiências e dos processos de aprendizado de cada indivíduo. 0 conhecimento explícito, ao contrário, é todo tipo de conhecimento formalizado que pode ser externalizado a partir do banco de dados, manuais, incorporados aos processos, produtos e serviços.

Para Davenport e Prusak (1999), o conhecimento tácito é subjetivo e individual e, nesse sentido, o processo de transferência depende basicamente da interação entre indivíduos, por isso, ambientes informais, onde as pessoas conversam sobre vários assuntos, são facilitadoras para o processo de transferência do conhecimento. Nas organizações do conhecimento, as estruturas hierárquicas não são divisões que delimitam diferenças de saberes, pois as pessoas com conhecimentos diferenciados não dependem da função ou cargo que ocupam. 
Ainda, segundo os autores, a identificação de uma hierarquia baseada na competência das pessoas é possivel a partir de um mapeamento das competências, que se apresenta de forma tácita, a partir de pesquisas que buscam, a partir de entrevistas, identificar onde as pessoas procuram as informações que podem auxiliar nas tarefas e assim sucessivamente, como uma espécie de bola de neve, em que as próximas pessoas a serem pesquisadas são as indicadas pelos entrevistados.

A gestão do conhecimento está se tornando uma dinâmica em diversas áreas. Nesse estudo, analisou-se o tema relacionado à agricultura familiar e às demais comunidades do meio rural. Na agricultura familiar, o conhecimento sempre esteve sob o domínio das pessoas, que realizam todo o ciclo da produção, desde a escolha do produto a ser cultivado, a forma de manejo, a colheita, o armazenamento até a comercialização. Dentro das restrições naturais, o grupo familiar possuía autonomia para realizar todas as tarefas seguindo uma forma própria de conhecimento desenvolvido a partir da experiência.

Ploeg (2014, p. 10) destaca que "o estabelecimento familiar é uma instituição atrativa, já que proporciona uma relativa autonomia à família agricultora, que ali busca alcançar uma dupla liberdade: estar livre de relações de exploração exercidas por agentes externos e estar livre para fazer as coisas a sua maneira".

A agricultura familiar começou a receber interferências externas de grandes corporações, no período denominado de Revolução Verde, iniciado a partir de 1966, que tinha como objetivo o desenvolvimento da agricultura a partir da inserção de novas tecnologias. Essa nova perspectiva voltada exclusivamente para o desenvolvimento econômico trouxe enormes problemas para os agricultores familiares que desempenhavam suas atividades não apenas como forma de obtenção de recursos econômicos, mas como meio de vida. O conhecimento local foi ignorado e desqualificado, por isso foi substituído pelo conhecimento técnico-científico a partir da inserção dos chamados pacotes tecnológicos, que visavam ao aumento da produtividade e à melhoria na rentabilidade (HOFFMANN; KAGEYAMA, 1984; WANDERLEY, 2000; MEDEIROS; WILKINSON; LIMA, 2002; WANDERLEY, 2009; ALMEIDA, 2015).

Para Wesz Júnior e Trentin (2006), a modernização tecnológica na agricultura, que estimulava basicamente a produção de soja, milho e trigo, desestruturou a forma de produção dos agricultores tradicionais. 0 incentivo a monocultura, visando ao favorecimento para a produção para fins mercantis, trouxe como consequência problemas para a sustentabilidade das famílias, tendo em vista que, junto com o incentivo à produção de produtos voltados à exportação, baseado na monocultura, criou-se a necessidade da aquisição de equipamentos, que devido à sazonalidade de produção acabavam sendo subutilizados. Ainda segundo os autores, esse sistema de produção ocasionou o endividamento dos pequenos produtores, prejudicou a fertilidade do solo e, devido à falta de bens de consumo local, houve a necessidade de que fossem adquiridos produtos externos à região. 
A política de desenvolvimento rural, com uma visão reducionista, começou a ser questionada na medida em que era discriminatória e beneficiava apenas os grandes produtores rurais. Com isso, os agricultores familiares ficaram excluídos da política de desenvolvimento, restando a eles a continuação de suas atividades sem qualquer espécie de incentivos e tendo necessidade de buscar alternativas de renda em outras atividades. Nesse cenário, os agricultores tornavam-se mão-de-obra das fazendas ou migraram para as periferias das cidades para trabalhar em atividades temporárias ou ser mais uma força de trabalho para as indústrias.

Diante disso, segundo Paz (2008), uma proposta de desenvolvimento deve estar voltada para a perspectiva dos territórios, considerando as diversidades econômicas e sociais. No novo paradigma de desenvolvimento, devem-se buscar alternativas para o aumento da eficiência e as contribuições positivas de práticas ambientalmente corretas dos agricultores tradicionais.

Para Altafin (2007), a agricultura familiar apresenta múltiplas funções em relação aos aspectos econômicos e sociais dos territórios. A primeira contribuição está relacionada à sua grande importância para a segurança alimentar. A geração de emprego é outra função muito importante, como a contribuição em relação aos aspectos sociais, tendo em vista que as propriedades familiares proporcionam muitos empregos nas áreas rurais. Outra função, que apresenta controvérsias, é a preocupação da agricultura familiar com a preservação do meio ambiente. De maneira geral, a agricultura é uma das principais responsáveis pelos problemas ambientais, consequência das políticas de modernização, destinadas às grandes propriedades, que visavam ter o máximo de lucratividade; exploram o meio ambiente e destroem de maneira indiscriminada os recursos naturais. Por outro lado, a agricultura familiar tem tido uma relação harmônica com a natureza, considerando a propriedade de terras como um patrimônio da família. Essa relação pode ser alterada e passar a ser prejudicial ao meio ambiente, na medida em que ocorrer um desiquilíbrio, devido à dificuldade de acesso e à escassez de terras.

Com as novas políticas voltadas para o desenvolvimento sustentável, o dilema agricultura convencional versus agricultura familiar passou a fazer parte das discussões no meio acadêmico. Pesquisadores e extensionistas, a partir de estudos junto com as comunidades rurais, identificaram a importância dos conhecimentos tradicionais, também denominados de local ecológico entre outras denominações, como parte fundamental das políticas de desenvolvimento rural sustentável.

Parte-se do princípio de que a modernização agrícola foi altamente discriminatória e com uma visão reducionista. Os conhecimentos tradicionais das populações rurais foram ignorados e considerados atrasados. No entanto, esse tipo de percepção disciplinar, considerando o saber técnico-científico como forma de saber absoluto, nos últimos anos, vem perdendo sua hegemonia diante das novas pesquisas que identificaram a importância dos conhecimentos das populações rurais para elaboração de políticas 
voltadas para o desenvolvimento rural sustentável. Diante disso, pode-se questionar: qual a discussão científica internacional sobre a valorização dos conhecimentos dos agricultores familiares e demais comunidades rurais para a promoção do desenvolvimento rural sustentável?

O presente estudo procurou responder a essa pergunta a partir de uma revisão sistemática da literatura internacional, tendo como objetivo analisar as discussões científicas sobre a valorização dos conhecimentos dos agricultores familiares e demais comunidades rurais para promoção do desenvolvimento rural sustentável.

\subsection{METODOLOGIA}

A presente pesquisa caracteriza-se como estudo bibliográfico. De acordo com Cervo e Bervian (2002), esse tipo de pesquisa busca informações a partir de referências teóricas de estudos passados sobre temas e problemas que o pesquisador está investigando.

A pesquisa bibliográfica foi realizada junto às bases de dados visando identificar trabalhos que estabelecessem relação entre gestão do conhecimento, agricultura familiar e população rural. As palavraschave utilizadas para busca foram: gestão do conhecimento e agricultura familiar e em inglês, knowledge management and family farming.

As bases de dados analisadas foram: Web Science e Scopus, e as brasileiras, Periódicos da CAPES, Biblioteca Digital Brasileira de Teses e Dissertações (BDTD) e Bases de Dados do Programa de PósGraduação em Engenharia e Gestão do Conhecimento (EGC) Florianópolis - Brasil. No BDTD, foram pesquisadas somente teses e no EGC, delimitou-se a busca por dissertações e teses da área de concentração em Gestão do conhecimento. Não foi estabelecida uma delimitação de ano para a busca dos trabalhos nos bancos de dados haja vista a gestão do conhecimento ser considerada um tema ainda novo na literatura.

Os critérios de inclusão e exclusão seguiram as seguintes etapas:

$1^{\text {a }}$ etapa: identificação no título e no resumo os estudos que abordassem tema sobre gestão do conhecimento e atividades desenvolvidas por agricultores de pequeno porte e demais populações tradicionais do meio rural.

$2^{\text {a }}$ etapa: leitura seletiva para identificar os trabalhos que abordassem concomitantemente assuntos sobre conhecimentos e agricultura familiar ou de pequeno porte e outras atividades desenvolvidas nas comunidades rurais.

$3^{\text {a }}$ etapa: por último, ocorreu uma leitura mais criteriosa dos artigos e teses, selecionados na segunda etapa, e assim foram descartados os estudos que não estabeleciam a relação entre os dois temas de maneira efetiva. 


\section{Gestãoe \\ Desenvolvimento}

O Quadro 1 apresenta tanto os resultados das buscas nas bases de dados como a quantidade de trabalhos selecionados em cada etapa, conforme critério estabelecido.

Quadro 1 - Quadro etapas dos critérios de escolha dos trabalhos

\begin{tabular}{|l|l|l|l|l|}
\hline Bases de dados & $\begin{array}{l}\text { Quantidade } \\
\text { trabalhos }\end{array}$ & $\mathbf{1}^{\mathbf{a}}$ etapa & $\mathbf{2}^{\mathbf{a}}$ etapa & $\mathbf{3}^{\mathbf{a}}$ etapa \\
\hline Capes & 588 & 30 & 23 & 3 \\
\hline BDTD & 371 & 36 & 14 & 3 \\
\hline BD - EGC & 233 & 33 & 7 & 3 \\
\hline Web Science & 174 & 7 & 4 & 4 \\
\hline SCOPUS & 161 & 11 & 7 & 4 \\
\hline
\end{tabular}

Fonte: Elaborado pelos autores.

\section{ESTUDOS BIBLIOGRÁFICOS}

Após análise dos trabalhos, verificou-se que as pesquisas destacaram a relevância dos conhecimentos oriundos da experiência, transmitidos de geração para geração, para o desenvolvimento das atividades econômicas de forma sustentável da agricultura familiar e demais comunidades rurais. Esse conhecimento recebeu várias denominações conforme Quadro 2.

\begin{tabular}{|l|l|}
\hline \multicolumn{1}{|c|}{ Quadro 2 - Denominações atribuídas ao conhecimento } \\
\hline Conominações atribuídas ao conhecimento & \multicolumn{1}{|c|}{ Autores } \\
\hline Conhecimento ecológico tradicional ou local & Zuchiwschi et al. (2010) \\
\hline Conheco tradicional & Glasenapp; Thornton (2011) \\
\hline Saber tradicional & Castro et (2013) \\
\hline Conhecimento ecológico local (CEL) & Santos; Soares e Barros (2015) \\
\hline Conhecimento empírico (tradicional, local, popular) & Thé (2003) \\
\hline Saberes implícitos & Marques (2009) \\
\hline Conhecimento tradicional & Viegas (2009) \\
\hline Conhecimento operacional & $\begin{array}{l}\text { Feliciano (2013); Pimenta (2017); Tricaud; Pinton e Pereira } \\
\text { (2016); Silva (2017) }\end{array}$ \\
\hline
\end{tabular}

Fonte: elaborado pelos autores. 


\section{Gestãoe \\ Desenvolvimento}

e-ISSN: 2446-6875

p-ISSN: 1807-5436

No Quadro 3, apresentam-se os objetivos e resultados dos artigos pesquisados.

Quadro 3 - Objetivos e resultados dos artigos

\begin{tabular}{|c|c|c|c|}
\hline Autor (es)/Título & Ano/Pais & $\begin{array}{l}\text { Campo da pesquisa/ } \\
\text { denominação do } \\
\text { conhecimento }\end{array}$ & Objetivos/Resultados \\
\hline $\begin{array}{l}\text { Mémoire des catastrophes, } \\
\text { gestion des risques et } \\
\text { architecture paysanne en } \\
\text { montagne. L'exemple des } \\
\text { vallées du Haut-Lavedan } \\
\text { dans les Pyrénées centrales } \\
\text { françaises } \\
\text { Monique Barrué-Pastor, M. } \\
\text { Michel Barrué }\end{array}$ & $\begin{array}{c}1998 \\
\text { França }\end{array}$ & $\begin{array}{l}\text { Vales de Haut-La- } \\
\text { vedan (Barèges e } \\
\text { Gèdres- Gavarnie) } \\
\text { nos Pireneus } \\
\text { franceses } \\
\text { Conhecimento local }\end{array}$ & $\begin{array}{l}\text { O estudo analisou junto às antigas famílias agrícolas dos } \\
\text { vales de Haut-Lavedan no Pirineus centrais franceses } \\
\text { as memórias de desastres e como eram elaboradas } \\
\text { as arquiteturas das residências e a proteção contra as } \\
\text { avalanches. Como resultado, o autor identificou, a partir } \\
\text { de relatos dos moradores, a existência de um importante } \\
\text { conhecimento local sobre arquitetura de construções e } \\
\text { formação de barreiras próximas às residências para evitar } \\
\text { os impactos das avalanches. Ainda, segundo os autores, } \\
\text { vários estudos têm sido realizados nessas regiões, mas } \\
\text { não existe uma articulação entre os saberes técnico- } \\
\text { científicos e o conhecimento local. }\end{array}$ \\
\hline $\begin{array}{l}\text { Limitações ao uso de } \\
\text { espécies florestais nativas } \\
\text { podem contribuir com a } \\
\text { erosão do conhecimento } \\
\text { ecológico tradicional e local } \\
\text { de agricultores familiares } \\
\text { Elaine Zuchiwschi; Alfredo } \\
\text { Celso Fantini; Antônio Carlos } \\
\text { Alves; Nivaldo Peroni }\end{array}$ & $\begin{array}{l}2010 \\
\text { Brasil }\end{array}$ & $\begin{array}{l}\text { Agricultores } \\
\text { familiares do } \\
\text { município de Anchieta } \\
\text { - SC } \\
\text { Conhecimento } \\
\text { ecológico tradicional } \\
\text { ou local }\end{array}$ & $\begin{array}{l}\text { O estudo teve como objetivo analisar o uso e o } \\
\text { conhecimento de agricultores familiares do município } \\
\text { de Anchieta Santa Catarina, sobre espécies vegetais das } \\
\text { florestas nativas. O resultado da pesquisa demonstra } \\
\text { que os agricultores ainda preservam conhecimento sobre } \\
\text { espécies nativas daregião. A pesquisa constatou que existe } \\
\text { um processo de perda gradual desses conhecimentos, } \\
\text { como uma das causas está o rigor da legislação ambiental } \\
\text { que restringe a extração de recursos das florestas nativas, } \\
\text { com isso, os agricultores perdem o contato com a natureza } \\
\text { e consequentemente os conhecimentos tradicionais, pois } \\
\text { eles se mantêm somente pela prática cotidiana. }\end{array}$ \\
\hline $\begin{array}{l}\text { Traditional Ecological } \\
\text { Knowledge of Swiss Alpine } \\
\text { Farmers and their Resilience } \\
\text { to Socioecological Change } \\
\text { Markus von Glasenapp; } \\
\text { Thomas F. Thornton }\end{array}$ & $\begin{array}{l}2011 \\
\text { Îndia }\end{array}$ & $\begin{array}{l}\text { Resiliência dos } \\
\text { domicílios agrícolas } \\
\text { em relação à } \\
\text { mudança climática } \\
\text { na aldeia de Vals, dos } \\
\text { Alpes da Suíça } \\
\text { Conhecimento } \\
\text { ecológico tradicional }\end{array}$ & $\begin{array}{l}\text { Este estudo avaliou a resiliência dos domicilios agrícolas } \\
\text { em relação à mudança climática na aldeia de Vals, } \\
\text { Suíça. De acordo com o estudo, os conhecimentos } \\
\text { acumulados das populações residentes nessas áreas de } \\
\text { riscos podem contribuir para aumentar a capacidade de } \\
\text { resiliência em relação às mudanças ambientais. Nesse } \\
\text { sentido, o conhecimento tradicional deve co-evoluir com } \\
\text { o conhecimento científico nas "práticas para a gestão } \\
\text { da mudança ecológica nos Alpes e outros ambientes" e } \\
\text { ainda deve-se "capacitar os portadores de conhecimento } \\
\text { tradicional para torná-los praticantes e tomadores de } \\
\text { decisão ao invés de meras partes interessadas". }\end{array}$ \\
\hline
\end{tabular}




\section{Gestãoe \\ Desenvolvimento}

e-ISSN: 2446-6875

p-ISSN: $1807-5436$

(Continuação)

Quadro 3 - Objetivos e resultados dos artigos

\begin{tabular}{|c|c|c|c|}
\hline Autor (es)/Título & Ano & $\begin{array}{c}\text { Campo da pesquisa/ } \\
\text { denominação do } \\
\text { conhecimento }\end{array}$ & Objetivos/Resultados \\
\hline $\begin{array}{l}\text { Fatores determinantes em } \\
\text { processos de transferência } \\
\text { de conhecimento: um } \\
\text { estudo de caso na Embrapa } \\
\text { Milho e Sorgo e firmas } \\
\text { licenciadas } \\
\text { José Márcio de Castro; } \\
\text { Daniela Martins Diniz; } \\
\text { Roberto Gonzalez Duarte; } \\
\text { Marcelo Dressler }\end{array}$ & $\begin{array}{l}2013 \\
\text { Brasil }\end{array}$ & $\begin{array}{l}\text { EMBRAPA Milho e } \\
\text { Sorgo } \\
\text { Conhecimento técnico - } \\
\text { científico }\end{array}$ & $\begin{array}{l}\text { O objetivo do estudo foi identificar e analisar o papel dos fatores } \\
\text { antecedentes no processo de transferência de conhecimento } \\
\text { interorganizacional. Foram analisados os fatores do contexto } \\
\text { relacional e fatores do contexto organizacional. Como } \\
\text { resultado, identificou-se que tanto por parte do emissor como } \\
\text { do receptor, o contexto relacional e organizacional pode afetar } \\
\text { negativamente o processo de transferência de conhecimentos. } \\
\text { De acordo com os autores, a maior contribuição desse estudo } \\
\text { para a literatura foi a análise do processo de transferência de } \\
\text { conhecimento a partir de uma perspectiva multidimensional, } \\
\text { ou seja, são diversos fatores que interferem no processo de } \\
\text { transferência de conhecimento, tanto por parte do emissor } \\
\text { como do receptor. }\end{array}$ \\
\hline $\begin{array}{l}\text { Atividade pesqueira e } \\
\text { construção de embarcações } \\
\text { na colônia de pescadores } \\
\text { z-18 do município de União/ } \\
\text { Pl, Brasil. } \\
\text { K. P. P. Santos; R. R. Soares; } \\
\text { R. F. M. Barros }\end{array}$ & $\begin{array}{l}2015 \\
\text { Brasil }\end{array}$ & $\begin{array}{l}\text { Comunidade de } \\
\text { pescadores Z-18, do } \\
\text { município de União/PI } \\
\text { Saber tradicional }\end{array}$ & $\begin{array}{l}\text { A pesquisa foi desenvolvida com a finalidade de coletar } \\
\text { informações etnobiológicas a respeito das artes e estratégias } \\
\text { de pesca, produto pescado, e ainda descrever as técnicas } \\
\text { utilizadas na construção e reparo de canoas da comunidade. } \\
\text { Os resultados demonstraram que os pescadores artesanais } \\
\text { possuem amplo conhecimento sobre a atividade que } \\
\text { desenvolvem e, esses conhecimentos são transmitidos de } \\
\text { "geração em geração, pela oralidade e prática diária". }\end{array}$ \\
\hline $\begin{array}{l}\text { O conhecimento local sobre } \\
\text { a fauna edáfica e suas } \\
\text { relações com o solo em } \\
\text { agroecossistema familiar de } \\
\text { base ecológica: um estudo } \\
\text { de caso } \\
\text { Greice de Almeida Schiavon, } \\
\text { Ana Cláudia Rodrigues de } \\
\text { Lima, Gustavo Schiedeck, } \\
\text { José Ernani Schwengber, } \\
\text { Ryan Noremberg Schubert, } \\
\text { Caroline Voser Pereira }\end{array}$ & $\begin{array}{l}2015 \\
\text { Brasil }\end{array}$ & $\begin{array}{l}\text { Propriedade agrícola } \\
\text { familiar de base } \\
\text { ecológica localizada } \\
\text { no distrito Rincão } \\
\text { da Caneleira, Morro } \\
\text { Redondo, Rio Grande } \\
\text { do Sul } \\
\text { Conhecimento local }\end{array}$ & $\begin{array}{l}\text { O objetivo do estudo foi analisar o conhecimento local sobre } \\
\text { a fauna edáfica e as práticas de manejo do solo no sistema } \\
\text { de produção de hortaliças. A pesquisa foi realizada com } \\
\text { uma família de agricultores e demonstrou que esta possui } \\
\text { um vasto conhecimento sobre a fauna edáfica. Apesar } \\
\text { disso, os resultados da pesquisa demonstraram que existe } \\
\text { a necessidade da socialização desses conhecimentos } \\
\text { com outros tipos de conhecimentos, proporcionando com } \\
\text { isso, agregação de valor na produção desenvolvida pelos } \\
\text { agricultores familiares. Nesse sentido, o autor conclui que "o } \\
\text { conhecimento local é um importante aliado ao conhecimento } \\
\text { acadêmico". }\end{array}$ \\
\hline
\end{tabular}


(Continuação)

Quadro 3 - Objetivos e resultados dos artigos

\begin{tabular}{|c|c|c|c|}
\hline Autor (es)/Título & Ano & $\begin{array}{c}\text { Campo da } \\
\text { pesquisa/ } \\
\text { denominação } \\
\text { do } \\
\text { conhecimento }\end{array}$ & Objetivos/Resultados \\
\hline $\begin{array}{l}\text { Sustainability: } \\
\text { Barilla's Innovative } \\
\text { Approach to } \\
\text { Sustainable } \\
\text { Farming } \\
\text { Stefano Pogutz; } \\
\text { Monika I. Winn }\end{array}$ & $\begin{array}{c}2016 \\
\text { Australia }\end{array}$ & $\begin{array}{l}\text { Barilla Group, } \\
\text { empresa } \\
\text { familiar líder } \\
\text { global no } \\
\text { mercado } \\
\text { de massas } \\
\text { alimentícias } \\
\text { Conhecimento } \\
\text { local }\end{array}$ & $\begin{array}{l}\text { A pesquisa teve como objetivo analisar como a interação do conhecimento } \\
\text { ecológico, desenvolvido internamente ou fora das organizações, pode contribuir } \\
\text { para o estabelecimento de princípios ecológicos sólidos para o sucesso das } \\
\text { organizações A pesquisa analisou um caso de um italiano produtor de alimento } \\
\text { que desenvolve um projeto de agricultura sustentável e integra os pequenos } \\
\text { agricultores com seus conhecimentos ecológicos com os demais conhecimentos } \\
\text { técnico-científicos. Como resultado, verificou-se que a integração entre os } \\
\text { conhecimentos ecológicos e científicos proporcionaram a inserção de práticas } \\
\text { sustentáveis na indústria agroalimentar, reduzindo com isso o impacto ambiental } \\
\text { no processo de produção da matéria-prima. }\end{array}$ \\
\hline $\begin{array}{l}\text { Study on } \\
\text { knowledge level of } \\
\text { the Tribal Farmers } \\
\text { Regarding Seed } \\
\text { Production and } \\
\text { Management } \\
\text { in Surguja and } \\
\text { Surajpur Districts of } \\
\text { Chhattisgarh, India } \\
\text { Akanksha Pandey } \\
\text { and M. L. Sharma }\end{array}$ & $\begin{array}{l}2016 \\
\text { Índia }\end{array}$ & $\begin{array}{l}\text { Agricultores } \\
\text { tribais dos } \\
\text { distritos de } \\
\text { Chhattisgarh } \\
\text { em Surguja e } \\
\text { Surajpur - India } \\
\text { Conhecimento } \\
\text { operacional } \\
\text { (real) }\end{array}$ & $\begin{array}{l}\text { O estudo teve como objetivo conhecer o nível de conhecimento dos agricultores } \\
\text { tribais em relação ao manejo e à produção de sementes. Os autores destacam } \\
\text { que a preservação dos conhecimentos dos agricultores em relação ao manejo e à } \\
\text { produção de sementes é de extrema importância para a sobrevivência de muitas } \\
\text { populações. A pesquisa identificou que a extensão do conhecimento relacionado } \\
\text { às diversas etapas da produção e ao manejo necessita ser melhorada e, para isso, } \\
\text { o autor sugere que os agricultores desenvolvam maior consciência em relação } \\
\text { a sua importância para a preservação das sementes, evitando que a tecnologia } \\
\text { monopolize o manejo e a produção. Para isso, é necessário que os agricultores } \\
\text { tenham acesso a conhecimentos técnicos sobre o manejo a partir de programas } \\
\text { de treinamentos com conteúdo que possibilitam os agricultores a melhorarem os } \\
\text { conhecimentos sobre gestão e produção de sementes. }\end{array}$ \\
\hline $\begin{array}{l}\text { The Effects of } \\
\text { Economic Factors } \\
\text { and Knowledge } \\
\text { Management } \\
\text { Practices on the } \\
\text { Productivity of } \\
\text { Small Farmers } \\
\text { in the North of } \\
\text { Thailand } \\
\text { Nattachet } \\
\text { Pooncharoen }\end{array}$ & $\begin{array}{c}2016 \\
\text { Tailândia }\end{array}$ & $\begin{array}{l}\text { Pequenos } \\
\text { agricultores } \\
\text { Tailandeses } \\
\text { Conhecimento } \\
\text { local }\end{array}$ & $\begin{array}{l}\text { A pesquisa teve como objetivos procurar os fatores que afetam a produtividade } \\
\text { da terra dos pequenos agricultores e estudar o papel das práticas de gestão do } \\
\text { conhecimento nos processos de produção dos pequenos agricultores do norte da } \\
\text { Tailândia. A prática de gestão do conhecimento desenvolvida pelas comunidades } \\
\text { de agricultores da Tailândia ocorre, principalmente, a partir do compartilhamento } \\
\text { do conhecimento entre líderes de agricultores e as comunidades. Em relação } \\
\text { ao conhecimento interno, o compartilhamento ocorre informalmente entre os } \\
\text { membros da comunidade. } \\
\text { Como conclusão, o trabalho destaca que, tendo em vista a pequena quantidade } \\
\text { de terras, os fatores mais importantes para o aumento da produtividade dos } \\
\text { agricultores Tailandeses são a água e os fertilizantes. Os agricultores que possuem } \\
\text { maior capacidade de gestão destacam o trabalho, a água e os fertilizantes, e os } \\
\text { com menor capacidade destacam os fertilizantes e a produtividade da terra. }\end{array}$ \\
\hline
\end{tabular}




\section{Gestãoe \\ Desenvolvimento}

e-ISSN: 2446-6875

p-ISSN: 1807-5436

(Continuação)

Quadro 3 - Objetivos e resultados dos artigos

\begin{tabular}{|c|c|c|c|}
\hline Autor (es)/Título & Ano & $\begin{array}{l}\text { Campo da pesquisa/ } \\
\text { denominação do } \\
\text { conhecimento }\end{array}$ & Objetivos/Resultados \\
\hline $\begin{array}{l}\text { Saberes e práticas } \\
\text { locais dos produtores de } \\
\text { guaraná (Paullinia cupana } \\
\text { Kunth var. sorbilis) do } \\
\text { médio Amazonas: duas } \\
\text { organizações locais frente } \\
\text { à inovação } \\
\text { Solène Tricaud, Florence } \\
\text { Pinton, Henrique dos } \\
\text { Santos Pereira }\end{array}$ & $\begin{array}{l}2016 \\
\text { Brasil }\end{array}$ & $\begin{array}{l}\text { Comunidades } \\
\text { de agricultores } \\
\text { familiares, } \\
\text { localizadas na região } \\
\text { do médio Amazonas } \\
\text { Conhecimento } \\
\text { tradicional }\end{array}$ & $\begin{array}{l}\text { O objetivo da pesquisa foi examinar o futuro de duas } \\
\text { comunidades de agricultores familiares não indígenas, } \\
\text { produtoras de guaraná, localizadas na região do médio } \\
\text { Amazonas e sua capacidade de permanecer em um território } \\
\text { onde está localizada uma poderosa multinacional e uma } \\
\text { organização de pesquisa pública reconhecida. O autor salienta } \\
\text { que a modernização da agricultura, com os chamados pacotes } \\
\text { tecnológicos, não atraiu os agricultores pouco familiarizados } \\
\text { com as novas tecnologias. Como resultado da pesquisa, foi } \\
\text { identificado que, apesar da inserção tecnológica, os guaraná- } \\
\text { cultores preservam ainda os conhecimentos sobre práticas } \\
\text { tradicionais de manejo do guaraná. }\end{array}$ \\
\hline $\begin{array}{l}\text { Trabalho, agricultura } \\
\text { camponesa e produção } \\
\text { do conhecimento } \\
\text { agroecológico } \\
\text { Márcio Gomes da Silva }\end{array}$ & 2017 & $\begin{array}{l}\text { Pesquisa bibliográfica } \\
\text { Conhecimento } \\
\text { tradicional }\end{array}$ & $\begin{array}{l}\text { O objetivo do estudo foi analisar a produção do conhecimento } \\
\text { relacionado à agricultura de base agroecológica a partir das } \\
\text { contradições históricas do campo brasileiro. A pesquisa } \\
\text { bibliográfica demonstra que a produção de conhecimentos } \\
\text { agroecológicos está sustentada nas práticas desenvolvidas } \\
\text { pela forma como a agricultura é praticada pelos camponeses. } \\
\text { Dois aspectos são destacados pelo autor como princípios } \\
\text { básicos para a produção de conhecimento agroecológico: } \\
\text { resgate do conhecimento tradicional, pois "a partir do } \\
\text { conhecimento tradicional é possível estabelecer uma } \\
\text { reconexão com as formas tradicionais de se fazer agricultura, } \\
\text { de uso dos recursos locais, de forma que tanto o trabalho } \\
\text { quanto o conhecimento sejam compartilhados" e a mediação } \\
\text { das instituições de pesquisa e de Assistência Técnica e } \\
\text { Extensão Rural - ATER, "que devem incorporar métodos } \\
\text { participativos de construção do conhecimento, voltados para } \\
\text { os conhecimentos locais". }\end{array}$ \\
\hline
\end{tabular}

Fonte: elaborado pelos autores 


\section{Gestãoe \\ Desenvolvimento}

e-ISSN: 2446-6875

p-ISSN: 1807-5436

Quadro 4 - Objetivos e resultados das Teses

\begin{tabular}{|c|c|c|c|}
\hline Autor/Título & Ano & $\begin{array}{l}\text { Campo da pesquisa/ } \\
\text { Denominação do } \\
\text { conhecimento }\end{array}$ & Objetivos/Resultados \\
\hline $\begin{array}{l}\text { Conhecimento ecológico, } \\
\text { regras de uso e manejo } \\
\text { local dos recursos } \\
\text { naturais na pesca } \\
\text { do Alto-Médio São } \\
\text { Francisco, MG } \\
\text { Ana Paula Glinfoskoi Thé }\end{array}$ & 2003 & $\begin{array}{l}\text { Pescadores artesanais } \\
\text { comerciais do trecho } \\
\text { mineiro do Alto-Médio } \\
\text { São Francisco } \\
\text { Conhecimento ecológico } \\
\text { local (CEL) }\end{array}$ & $\begin{array}{l}\text { A pesquisa teve como objetivo identificar o conhecimento ecológico, } \\
\text { regras de uso e manejo local dos recursos naturais na pesca do Alto- } \\
\text { Médio São Francisco, MG. O estudo demonstrou que os pescadores } \\
\text { desenvolveram "um modelo percebido" sobre o comportamento dos } \\
\text { peixes envolvendo aspectos biológicos e ecológicos. Nesse sentido, de } \\
\text { acordo com o autor, o conhecimento local sobre o ambiente de pesca e os } \\
\text { recursos pesqueiros, acumulados pelos pescadores devido à sua prática } \\
\text { diária, não podem ser desconsiderados no estabelecimento de normas } \\
\text { ou regulamentações pesqueiras. "É necessário, sempre de forma crítica } \\
\text { e criteriosa, agregar valor a este saber empírico, dando-lhe o 'status' } \\
\text { de parceiro do conhecimento científico, nas formulações que visem dar } \\
\text { sustentabilidade à pesca profissional artesanal". }\end{array}$ \\
\hline $\begin{array}{l}\text { Atividades de gestão } \\
\text { do conhecimento na } \\
\text { elaboração do estudo de } \\
\text { impacto ambiental } \\
\text { Cláudia Viviane Viegas }\end{array}$ & 2009 & $\begin{array}{l}\text { Elaboradores de ElAs } \\
\text { no Rio Grande do Sul, } \\
\text { os quais integram } \\
\text { as consultorias mais } \\
\text { representativas nesta } \\
\text { área, em nível estadual } \\
\text { Saberes implícitos }\end{array}$ & $\begin{array}{l}\text { O objetivo do estudo foi propor uma estrutura de análise do EIA (Estudo de } \\
\text { Impacto Ambiental) relativa ao processo de construção do conhecimento } \\
\text { de seus elaboradores, considerando as relações entre conhecimentos } \\
\text { implícitos e explícitos. De acordo com o autor, os problemas ambientais } \\
\text { não podem ser dissociados dos problemas das pessoas, das suas visões e } \\
\text { percepções. Neste sentido, o conhecimento informal implíito é relevante } \\
\text { para a busca de soluções para os problemas ambientais. Como resultado, } \\
\text { o autor destaca que a elaboração do EIA deve ser vista como um processo } \\
\text { de construção do conhecimento que envolve a articulação dos saberes } \\
\text { formais, explícita e os saberes implíitos que não têm sido considerados } \\
\text { nos estudos sobre os problemas ambientais. }\end{array}$ \\
\hline $\begin{array}{l}\text { Velhos conhecimentos, } \\
\text { novos desenvolvimentos: } \\
\text { transições no regime } \\
\text { societário da agricultura. } \\
\text { A produção de novidades } \\
\text { entre agricultores } \\
\text { Produtores de Plantas } \\
\text { Medicinais no sul do } \\
\text { Brasil } \\
\text { Flavia Charão Marques }\end{array}$ & 2009 & $\begin{array}{l}\text { Agricultores na produção } \\
\text { ecológica de plantas } \\
\text { medicinais no Sul do Brasil } \\
\text { Conhecimento empírico } \\
\text { (tradicional, local, popular) }\end{array}$ & $\begin{array}{l}\text { O estudo teve como objetivo explorar a potencialidade da produção } \\
\text { de novidade para a promoção de transições no regime sociotécnico } \\
\text { dominante na agricultura, a partir da análise de novidades desenvolvidas } \\
\text { por agricultores na produção ecológica de plantas medicinais no Sul do país. } \\
\text { O trabalho demonstrou que, para o desenvolvimento de uma agricultura } \\
\text { sustentável, é necessária a transição do modelo vigente que, com o } \\
\text { processo de modernização agrícola, levou a uma homogeneização das } \\
\text { atividades agrícolas. Para a transição desse modelo orientado pelo "regime } \\
\text { sociotécnico, é necessária a retomada de uma agricultura com seu sentido } \\
\text { de "co-produção". O conhecimento desses produtores é denominado } \\
\text { de Conhecimento Empírico que envolve os conceitos utilizados como: } \\
\text { tradicional, local e popular). O estudo identificou a existência de novidades, } \\
\text { possibilitando com isso, estabelecimento de um nicho de inovação. Foi } \\
\text { detectada também a falta de alinhamento entre os atores para superar } \\
\text { as barreiras do regime dominante. A falta de alinhamento torna-se mais } \\
\text { acirrada quando os atores envolvidos são cientistas e agricultores. }\end{array}$ \\
\hline
\end{tabular}


Quadro 4 - Objetivos e resultados das Teses

\begin{tabular}{|c|c|c|c|}
\hline Autor/Título & Ano & $\begin{array}{l}\text { Campo da pesquisa/ } \\
\text { Denominação do } \\
\text { conhecimento }\end{array}$ & Objetivos/Resultados \\
\hline $\begin{array}{l}\text { Avifauna } \\
\text { Pantaneira: } \\
\text { diálogos } \\
\text { de saberes } \\
\text { científicos e } \\
\text { populares em } \\
\text { áreas úmidas } \\
\text { (São Pedro } \\
\text { de Joselândia, } \\
\text { Barão de } \\
\text { Melgaço, MT } \\
\text { Samuel Borges } \\
\text { de Oliveira } \\
\text { Júnior }\end{array}$ & 2011 & $\begin{array}{l}\text { Pantanal Mato- } \\
\text { grossense } \\
\text { Conhecimento local }\end{array}$ & $\begin{array}{l}\text { O objetivo da pesquisa foi revelar que a comunidade pantaneira de São } \\
\text { Pedro de Josselândia ainda mantém uma forte relação com o ambiente ao } \\
\text { qual está inserida, evidenciada pela cultura local e pelos saberes de seus } \\
\text { moradores, com destaque aos saberes sobre a avifauna local. Os resultados } \\
\text { demonstraram que, a partir do conhecimento local, os moradores possuem } \\
\text { um vasto conhecimento sobre espécies de pássaros. Esses conhecimentos } \\
\text { são importantes para a comunidade pantaneira, na medida em que são } \\
\text { identificadas as espécies que possuem utilidade alimentar bem como as que } \\
\text { se referem a aspectos culturais onde determinadas espécies possuem valor } \\
\text { simbólico para os moradores. Ainda como resultado, o autor destaca que o } \\
\text { conhecimento local pode contribuir para a ciência na realização de inventários } \\
\text { das espécies, no caso dessa pesquisa, a quantidade de espécies de pássaros } \\
\text { existentes no Pantanal Mato-grossense. }\end{array}$ \\
\hline $\begin{array}{l}\text { Extensão } \\
\text { rural: criação, } \\
\text { estratégias } \\
\text { de uso e } \\
\text { retenção do } \\
\text { conhecimento } \\
\text { Antônio Marcos } \\
\text { Feliciano }\end{array}$ & 2013 & $\begin{array}{l}\text { Atores da extensão } \\
\text { rural pública brasileira, } \\
\text { organizações, técnicos } \\
\text { extensionistas e } \\
\text { especialistas em } \\
\text { extensão rural } \\
\text { Conhecimento } \\
\text { tradicional }\end{array}$ & $\begin{array}{l}\text { O objetivo da pesquisa foi estabelecer diretrizes para os processos de criação, } \\
\text { estratégias de uso e retenção do conhecimento para organizações de extensão } \\
\text { rural. O autor destaca a importância que os técnicos e extensionistas têm } \\
\text { nesse processo, tendo em vista o contato direto desses com os agricultores. } \\
\text { Conforme o autor, a busca pelo desenvolvimento rural sustentável, a partir dos } \\
\text { novos conteúdos contidos no PNATER (Plano Nacional de Assistência técnica } \\
\text { e extensão rural), passa pela valorização dos conhecimentos tradicionais. } \\
\text { Como resultado, foi identificado um distanciamento entre as organizações de } \\
\text { extensão rural com relação à realidade onde atuam. Também foi constatada a } \\
\text { falta de valorização do conhecimento como fator importante para o aumento } \\
\text { da competitividade, devido ao desconhecimento dos métodos e técnicas } \\
\text { relacionados à gestão do conhecimento. }\end{array}$ \\
\hline $\begin{array}{l}\text { Análise de } \\
\text { maturidade da } \\
\text { coprodução de } \\
\text { conhecimento } \\
\text { transdisciplinar: } \\
\text { um estudo } \\
\text { de caso em } \\
\text { uma rede } \\
\text { agroecológica } \\
\text { Rosângela } \\
\text { Borges Pimenta }\end{array}$ & 2017 & $\begin{array}{l}\text { Participantes do } \\
\text { Projeto SEMECOL - } \\
\text { Produção de Semente } \\
\text { Própria em Sistemas } \\
\text { de Base Ecológica por } \\
\text { Agricultores Familiares } \\
\text { no Estado do Paraná. } \\
\text { Conhecimento } \\
\text { tradicional }\end{array}$ & $\begin{array}{l}\text { O objetivo da pesquisa foi propor um instrumento de análise de maturidade } \\
\text { para o processo de coprodução de conhecimento na pesquisa transdisciplinar. } \\
\text { Para a execução da pesquisa, as redes agroecológicas foram adotadas como } \\
\text { campo de estudo, tendo em vista que essas são formadas na perspectiva } \\
\text { transdisciplinar, pois vários atores estão envolvidos no processo. Conforme o } \\
\text { autor, com isso, os diversos saberes são envolvidos, tanto o conhecimento } \\
\text { científico como o tradicional passam a fazer parte do processo de criação do } \\
\text { conhecimento. Como resultado ao objetivo, um instrumento foi criado que } \\
\text { consistiu em um questionário composto por três etapas visando analisar } \\
\text { as dimensões que foram identificadas no processo de coprodução em uma } \\
\text { perspectiva transdisciplinar. }\end{array}$ \\
\hline
\end{tabular}

Fonte: elaborado pelos autores. 


\section{CONSIDERAÇÕES FINAIS}

Na sequência, apresentam-se os principais resultados dos artigos e Teses.

A tese de doutorado de Thé (2003) concluiu que os pescadores artesanais possuem amplo conhecimento sobre regras de uso e manejo local dos recursos naturais na pesca. Esses conhecimentos são oriundos a partir do modelo percebido sobre a realidade, criando assim uma espécie de normas que servem para regulamentar a interação das pessoas com o ambiente natural. Nessa perspectiva, segundo o autor, os órgãos públicos deveriam valorizar os conhecimentos das comunidades rurais nos projetos de desenvolvimento a partir de ações que permitissem uma interação entre os conhecimentos locais e técnico-científicos.

Os autores Santos, Soares e Barros (2015) também têm como campo de pesquisa atividades de pesca. Como resultado, os autores verificaram que os pescadores possuem vasto conhecimento sobre artes e estratégias de pesca e na construção de embarcações. Essas atividades são desenvolvidas não apenas como forma de obtenção de recursos para sobrevivência das famílias, mas também como meio de vida. Representam um grupo que não está focado de maneira restrita nas atividades econômicas que realizam e não são resistentes às mudanças, ao contrário, é "um grupo cultural ansioso para se capacitar, para negociar, gerenciar e cuidar do recurso pesqueiro, além de contribuir para uma sociedade de forma sustentável".

O estudo de Schiavon et al. (2015) trata sobre fauna edáfica e as práticas de manejo do solo no sistema de produção de hortaliças desenvolvida por uma família de agricultores. Como conclusão, destaca-se que os agricultores possuem vastos conhecimentos sobre as atividades que desenvolvem. No entanto, em alguns aspectos, a produção poderia ser melhorada se houvesse a contribuição de outros conhecimentos.

A pesquisa de Oliveira Júnior (2011) trata sobre os conhecimentos de moradores pantaneiros sobre avifauna local. A pesquisa demonstrou que esses moradores possuem conhecimentos sobre uma diversidade de espécies de pássaros nativos da região. Os conhecimentos foram adquiridos a partir da convivência com a natureza e socializados entre as pessoas. Com isso, segundo o autor, esses saberes, apesar de não serem resultantes de pesquisa, possuem grande relevância para a pesquisa científica. Nesse sentido, destaca-se a importância de se desenvolver o "diálogo entre os saberes locais e os saberes universais".

Silva (2017), a partir de sua pesquisa bibliográfica sobre como se fundamenta o conhecimento agroecológico, destaca que esse tipo de conhecimento provém da forma de interação com o ambiente natural, praticada pelos camponeses. De acordo com o autor, as contribuições da Assistência Técnica 
e Extensão rural - ATER - são importantes para a reconstrução de uma agricultura sustentável, tendo em vista o fato de serem os agentes que mantêm contato próximo com a realidade das famílias dos agricultores e com isso são responsáveis por serem os mediadores durante o processo de integração entre os conhecimentos tradicionais e técnico-científicos.

A pesquisa dos autores Tricaud, Pinton e Pereira (2016) destaca o tema sobre a difusão tecnológica na agricultura, tema que nos últimos anos tem sido bastante discutido no meio acadêmico. De acordo com os autores, a tentativa de homogeneização da agricultura no entorno das inovações não impressionou os agricultores familiares. As empresas que tinham a função de serem as difusoras das inovações não obtiveram o sucesso almejado. Os próprios órgãos públicos de extensão rural também não assimilaram as novas abordagens participativas em que o processo de criação do conhecimento deve ser resultante da interação entre os conhecimentos técnico-científicos e os conhecimentos tradicionais das comunidades rurais.

Pimenta (2017) aborda o tema relacionado à questão da "coprodução" do conhecimento em projetos transdisciplinares e tem como referência para o estudo as redes de agroecologia, tendo em vista que esse sistema de produção envolve a participação de diversos atores. De acordo com o autor, o resultado almejado, a partir de estudos transdisciplinares, é a mudança de uma realidade concreta em que a criação do conhecimento é resultado de um processo de socialização entre o conhecimento tácito e explícito de todos os envolvidos com o problema. Nos estudos transdisciplinares, a partir da integração dos diversos saberes, é possivel uma melhor compreensão dos problemas bem como a identificação das causas e a busca por soluções.

Glasenapp e Thornton (2011) destacam a importância do conhecimento tradicional para a resiliência das populações que vivem em áreas rurais e que estão sujeitas a catástrofes resultantes de fenômenos naturais. De acordo com os autores, o conhecimento adaptativo deve "coevoluir" com o conhecimento científico. Nessa perspectiva, o novo conhecimento deve ser resultado do envolvimento das pessoas interessadas, residentes nessas áreas de riscos, proporcionando a elas a oportunidade de contribuir com seus conhecimentos. As novas formas de adaptação ao meio devem ser um processo contínuo de interação entre o conhecimento tradicional (tácito) e técnico-científico (explícito).

A pesquisa dos autores Barrué-Pastor e Barrué (1998) foi realizada a partir de uma análise da memória das pessoas residentes nos Alpes Franceses sobre os desastres, consequência das avalanches e sobre as arquiteturas das residências projetadas para suportar os impactos. A pesquisa demonstrou que as familias residentes próximas às montanhas desenvolveram importantes conhecimentos necessários para se adaptarem às condições adversas do local. Segundo os autores, as populações possuem grande confiança e valorizam seus conhecimentos, mas, por outro lado, percebem que não são reconhecidos na 
medida em que as ações são elaboradas pelos órgãos governamentais não são resultantes de diálogos entre os saberes locais e os demais conhecimentos.

Para Marques (2009), o desenvolvimento de uma agricultura sustentável depende da "coparticipação" dos diversos atores envolvidos. É nesse sentido que existem descompassos ou falta de alinhamentos entre o conhecimento desenvolvido pela ciência e o das populações das áreas rurais. De acordo com o autor, é necessária a formação de redes para superação desses entraves de maneira que o conhecimento seja compartilhado entre atores de diversas áreas. É preciso também adotar uma postura interdisciplinar e transdisciplinar para que ocorra a interação dos diversos tipos de conhecimento.

Pogutz e Winn (2016) também abordam a questão da agricultura sustentável. A pesquisa destaca a importância do conhecimento local em relação à prática de preservação do solo, como a rotação de cultura e a diversificação da produção. Os autores enfatizam a necessidade de que se articulem conhecimentos técnico-científicos com os tradicionais e ecológicos visando à redução dos impactos ambientais e ao mesmo tempo proporcionem benefícios para as organizações e as comunidades locais.

Feliciano (2013), em sua tese de doutorado sobre gestão do conhecimento, destaca a extensão rural como tema principal da pesquisa. Em sua análise, o autor verifica a relação entre os órgãos de Assistência técnica e extensão rural - ATER e os agricultores. Segundo o autor, a política de desenvolvimento da agricultura foi baseada em pressuposto de inserção da tecnologia, cabendo aos técnicos e extensionistas a função de transmissão dos conhecimentos técnico-científicos. Uma nova perspectiva sobre a forma de transferência de conhecimentos foi adotada com a criação da nova política para ATER que tem como um dos seus princípios o regate dos conhecimentos tradicionais. Eles se destacam como fundamentais para o desenvolvimento de uma agricultura sustentável baseada nos princípios da agroecologia.

A tese de Viegas (2009) estuda os impactos ambientais na perspectiva da gestão do conhecimento. $\mathrm{O}$ estudo analisa a interação entre conhecimento tácito e explicito na perspectiva dos especialistas. A autora destaca a importância da socialização dos conhecimentos entre as pessoas envolvidas no processo de elaboração de estudos de impacto ambiental. Nas análises, destaca-se a importância dos saberes implícitos no processo de elaboração dos novos conhecimentos.

O estudo de Pooncharoen (2016) destaca a prática de gestão do conhecimento como fator importante para a melhoria da qualidade de vida dos pequenos agricultores da Tailândia. A iniciativa governamental aposta no investimento da gestão do conhecimento como estratégia para o aumento da produtividade. Destaca que, a partir do compartilhamento do conhecimento, é possivel manter uma "coesão" entre os agricultores. Nesse estudo, dois tipos de conhecimentos são observados e utilizados no processo de criação de novos conhecimentos. O conhecimento explícito é socializado a partir dos líderes dos grupos, que são membros escolhidos para serem os mediadores dos novos conhecimentos junto aos 
agricultores. Segundo o autor, essa maneira de compartilhar os conhecimentos é realizada tendo em vista que o conhecimento agrícola é altamente complexo e depende da realidade local com seus diversos tipos de conhecimentos. Já o conhecimento tácito é compartilhado de maneira informal e internamente entre os membros da comunidade.

Pandey e Sharma (2016) ressaltam a importância da preservação do conhecimento sobre práticas de manejo que preservam o conhecimento sobre o cultivo de sementes sem a interferência dos processos tecnológicos. Os autores destacam a importância da preservação das práticas tradicionais de manejo e produção de sementes tendo em vista sua importância para a subsistência de muitas populações. Mas a preservação dessas atividades também requer a incorporação dos conhecimentos técnico-científicos para auxiliar os agricultores nos conhecimentos relacionados à gestão da produção.

Zuchiwschi et al. (2010) analisam os tipos de conhecimentos utilizados pelos agricultores familiares e demonstram que esses possuem amplo conhecimento sobre as espécies nativas da região. No entanto, os autores destacam que muitos desses conhecimentos estão se perdendo tendo em vista o distanciamento do homem com a natureza. Diversos fatores contribuem para isso, tais como o rigor das legislações ambientais que ao mesmo tempo busca a preservação do meio ambiente e faz com que a população local não tenha mais proximidade com a natureza.

Castro et al. (2013), em seus estudos, analisaram o processo de transferência do conhecimento interorganizacional. 0 estudo foi realizado entre uma empresa responsável pelo desenvolvimento de tecnologias para a produção agrícola e empresas licenciadas. Segundo os autores, na literatura, tem-se adotado uma perspectiva "unidimensional", em que a transferência do conhecimento depende de fatores únicos sem uma interferência de fatores contextuais. A outra perspectiva adotada recentemente privilegia uma perspectiva "multidimensional". Nesse cenário, o processo de transferência do conhecimento depende de vários fatores relacionados ao contexto das organizações ou do tipo de relações predominantes nos grupos sociais.

Em suma, os trabalhos analisados abordaram a questão do conhecimento relacionado às diversas atividades desenvolvidas nas áreas rurais. Os estudos de Thé (2003) e Santos, Soares e Barros (2015) trataram sobre conhecimento e comunidades de pescadores. Silva (2017) e Pimenta (2017) pesquisaram sobre conhecimento e agricultura agroecológica. Schiavon et al. (2015) e Oliveira Júnior (2011) estudaram sobre os conhecimentos relativos à fauna. Zuchiwschi et al. (2010) e Viegas (2009) pesquisaram sobre conhecimento e recursos naturais. Marques (2009), Pogutz e Winn (2016) estudaram a respeito da agricultura sustentável. Feliciano (2013) pesquisou sobre conhecimento e extensão rural. Glasenapp e Thornton (2011), Barrué-Pastor e Barrué (2016) trataram sobre conhecimento e resiliência nas áreas rurais. Pooncharoen (2016), Pandey e Sharma (2016) e Tricaud, Pinton e Pereira (2016) estudaram sobre 
conhecimento e manejo agrícola, e Castro et al. (2013) pesquisaram sobre conhecimento e tecnologia para produção agrícola.

Os trabalhos que analisaram a importância dos conhecimentos locais para desenvolvimento rural sustentável são recentes. Os resultados demonstram que a literatura sobre o tema se apresenta crítica à visão reducionista da ciência que considera o conhecimento técnico-científico como saber absoluto e que precisa ser transferido aos agricultores e às demais comunidades rurais. Foi possível observar que, em relação aos conhecimentos tradicionais, apesar de terem sido valorizados nos últimos anos, as políticas públicas voltadas para essas comunidades, na maioria das vezes, não estão buscando o diálogo entre os saberes técnico-científicos e os saberes tradicionais.

Vários fatores têm contribuído para que os conhecimentos das populações rurais despertassem interesse dos estudiosos. Entre eles o paradigma do desenvolvimento sustentável. A ideia de crescimento econômico como sinônimo de desenvolvimento se tornou insustentável, pois a partir de uma visão disciplinar, tentou-se homogeneizar as políticas de desenvolvimento, voltadas apenas para os aspectos econômicos sem considerar os aspectos socioambientais. Houve a necessidade de se adotar uma nova perspectiva de desenvolvimento alicerçado no tripé econômico, social e ambiental com o agravamento dos problemas ambientais, o uso indiscriminado dos recursos naturais e o aumento das desigualdades sociais.

Na revisão da literatura sobre o assunto, de maneira geral, foi ressaltada a necessidade de se resgatarem os conhecimentos tradicionais e a promoção do diálogo entre os diferentes tipos de saberes. Nesse sentido, a visão reducionista de se considerar a ciência como o saber universal perde sua hegemonia e cada vez mais os problemas relacionados à natureza devem ser analisados a partir de uma perspectiva sistêmica. A realidade é muito complexa para ser rotulada apenas pela concepção lógica e analítica das ciências. Os problemas econômicos e socioambientais devem ser analisados em uma perspectiva interdisciplinar e transdisciplinar. Com isso, busca-se a integração das pessoas com suas comunidades, preservando, com isso, a identidade local. Cada vez mais o conhecimento desenvolvido pelas comunidades rurais, independente das atividades desenvolvidas, é reconhecido pelos estudiosos como fundamental para a busca do desenvolvimento rural sustentável.

Diante dos estudos analisados, verificou-se que a pesquisa de Pooncharoen (2016) com pequenos agricultores Tailandeses é o único estudo que apresenta um modelo de gestão do conhecimento e, portanto, pode servir de referência para outras nações. A política do governo da Tailândia, voltada para os pequenos agricultores, prioriza a gestão do conhecimento, com isso, procura impulsionar a participação dos agricultores nos processos de desenvolvimento local, a partir do compartilhamento do conhecimento explícito (técnico-científico), oriundo do planejamento governamental, socializado a partir dos líderes com 
as comunidades, e articulado com os conhecimentos tácitos que são compartilhados de maneira informal entre as pessoas e as comunidades.

Esta pesquisa apresentou estudos da Ásia Meridional, Sudeste Asiático, Europa Ocidental, América do Sul e Oceania sobre a valorização dos conhecimentos dos agricultores familiares e demais comunidades rurais para o desenvolvimento rural sustentável. A partir da pesquisa, identificaram-se que, nos últimos anos, vários estudos demonstraram a necessidade de se encontrar meios de interação entre o conhecimento técnico-científico e os conhecimentos locais para que se desenvolvam políticas voltadas para o desenvolvimento rural sustentável.

É possivel observar nos estudos que as populações rurais ainda preservam os conhecimentos adquiridos a partir da experiência e que são transmitidos de geração em geração. No entanto, de acordo com os dados da pesquisa, apesar de, nos últimos anos, ter havido um reconhecimento dos saberes locais, nos processos de elaboração de políticas de desenvolvimento rural sustentável, ainda não há um envolvimento efetivo das comunidades rurais.

As pesquisas têm demonstrado também que os próprios extensionistas, que estão mais próximos dos agricultores, não estão preparados para exercer a função de colaboradores no processo de compartilhamento do conhecimento, pois ainda persiste o paradigma de que as populações rurais são atrasadas e que devem ser inseridas nos processos de desenvolvimento tecnológico, voltadas exclusivamente para o desenvolvimento econômico, considerando os conhecimentos locais irrelevantes.

Em relação ao processo de compartilhamento do conhecimento, não foram identificados estudos que analisassem a percepção dos agricultores familiares e demais população rural ou tradicional em relação à interação entre os conhecimentos técnico-científicos dos especialistas com os conhecimentos tradicionais dos agricultores familiares e demais comunidades rurais.

\section{REFERÊNCIAS}

ALMEIDA, J. Da ideologia do progresso à ideia de desenvolvimento (rural) sustentável, 2015. Disponível em: <https://www.researchgate.net/publication/237518300>. Acesso em: 10 jul. 2018.

ALTAFIN, I. Reflexões sobre o conceito de agricultura familiar, 2007. Disponível em: <emhttp://www. enfoc.org.br/system/arquivos/documentos/70/f1282reflexoes-sobre-o-conceito-de-agricultura-familiar---iara-altafin---2007.pdf>. Acesso em: 09 jul. 2018. 


\section{Gestãoe \\ Desenvolvimento}

e-ISSN: 2446-6875

p-ISSN: 1807-5436

BARRUÉ-PASTOR, M.; BARRUÉ, M. M. Mémoire des catastrophes, gestion des risques et architecture paysanne en montagne. L'exemple des vallées du Haut-Lavedan dans les Pyrénées centrales françaises. Revue de Géographie Alpine, v. 86, n. 2, p. 25-36, 1998.

CASTRO, J. M. de; DINIZ, D. M.; DRESSLER, M. Fatores determinantes em processos de transferência de conhecimentos: um estudo de caso na Embrapa Milho e Sorgo e firmas licenciadas. Rev. Adm. Pública, Rio de Janeiro, v. 47, n. 5, p. 1283-1306, 2013.

CERVO, A. L.; BERVIAN, P. A. Metodologia científica. $5^{a}$ ed. São Paulo: Prentice Hall, 2002.

DAVENPORT, T.; PRUSAK, L. Conhecimento empresarial. Rio de Janeiro: Campus; São Paulo, 1999.

DRUCKER, P. F. A administração na próxima sociedade. São Paulo: Nobel, 2002.

FELICIANO, A. M. Extensão rural: criação, estratégias de uso e retenção do Conhecimento. 2013. 367 f. Tese (Doutorado em Engenharia e Gestão do Conhecimento) - UFSC, Florianópolis, SC, 2013.

GLASENAPP, Markus von; THORNTON, Thomas F. Traditional ecological knowledge of swiss alpine farmers and their resilience to socioecological change. Hum Ecol, New Delhi, v. 39, n. 6, p. 769-781, 2001.

HOFFMANN, R.; KAGEYAMA, A. A. Modernização da agricultura e distribuição de renda no Brasil. Pesquisa e Planejamento Econômico, Rio de Janeiro, v. 15, n. 1, p. 171-208, 1985.

IBGE - Fundação instituto brasileiro de geografia e estatística. Censo agropecuário 2006. Disponível em: <http://bibliotecadigital.seplan.planejamento.gov.br/bitstream/handle/iditem/722/agro_2006.pdf?sequence=2>. Acesso em: 02 jul. 2018.

KITCHENHAM, B.; BRERETON, O. P.; BUDGEN, D.; TURNER, M.; BAILEY, J.; LINKMAN, S. Systematic literature reviews in software engineering - A systematic literature review. Information and Software Technology, v. 51, p. 7-15, 2009.

MARQUES, F. C. Velhos conhecimentos, novos desenvolvimentos: transições no regime sociotécnico da agricultura a produção de novidades entre agricultores produtores de plantas medicinais do Sul do Brasil. 2009. 220 f. Tese (Doutorado em Desenvolvimento rural), UFRGS, Porto Alegre, RS, 2009.

MEDEIROS, J. X. de; WILKINSON, J.; LIMA, D. M. de A. O desenvolvimento científico-tecnológico e a agricultura familiar. In: Lima, D. M. de; Wilkinson, J. (Orgs.). Inovação nas tradições da agricultura familiar. Brasília: CNPq/Paralelo 15, p. 23-38, 2002.

NONAKA, I.; TAKEUCHI, H. Criação de conhecimento na empresa. Rio de Janeiro: Elsevier, 1997. 


\section{Gestãoe \\ Desenvolvimento}

e-ISSN: 2446-6875

p-ISSN: $1807-5436$

OLIVEIRA JÚNIOR, S. B. de. Avifauna Pantaneira: diálogo de saberes científico e popular em áreas úmidas (São Pedro de Joselândia, Barão de Melgaço, MT). 2011. 115 f. Tese (Doutorado em Ciências) - UFSCAR, São Carlos, SP, 2011.

PANDEY, A.; SHARMA, M. L. Study on knowledge level of the tribal farmers regarding seed production and management in Surguja and Surajpur districts of Chhattisgarh, India. Plant Archives, v. 16, n. 2, p. 829-833, 2016.

PAZ, R. Mitos y realidades sobre la agricultura familiar en argentina: reflexiones para su discusión. Problemas del Desarrollo. v. 39, n. 153, p. 57-82, 2008.

PIMENTA, Rosângela Borges. Análise de maturidade da coprodução de conhecimento transdisciplinar: um estudo de caso em uma rede agroecológica. 2017. 240 f. Tese (Doutorado em Engenharia e Gestão do Conhecimento) - UFSC, Florianópolis, SC, 2017.

PLOEG, J. D. Van der. Dez qualidades da agricultura familiar. Cadernos de debate, São Paulo, n. 1, p. 1-16, fev. 2014.

POGUTZ, S.; WINN, M. I. Cultivating ecological knowledge for corporate sustainability: barilla's innovative approach to sustainable farming. Business Strategy and the Environment, v. 25, n. 6, p. 435-448, 2016

POONCHAROEN, N. The Effects of economic factors and knowledge management practices on the productivity of small farmers in the North of Thailand. International Business Management, v. 10, n. 4, p. 456-460, 2016

SANTOS, K. P. P; SOARES, R. R; BARROS, R. F. M. Atividade pesqueira e construção de embarcações na colônia de pescadores z-18 do município de União/PI, Brasil. Holos, v. 31, n. 6, p. 90-106, 2015.

SCHIAVON, G. de A. et al. O conhecimento local sobre a fauna edáfica e suas relações com o solo em agroecossistema familiar de base ecológica: um estudo de caso. Ciência Rural, Santa Maria, v. 45, n. 4, p. 658-660, 2015

SILVA, M. G. da. Trabalho, agricultura camponesa e produção do conhecimento agroecológico. Inter-Ação, Goiânia, v. 42, n. 2, p. 347-357, 2017.

THÉ, A. P. G. Conhecimento ecológico, regras de uso e manejo local dos recursos naturais na pesca do alto-médio São Francisco, MG. 2003. 197 f. Tese (doutorado em Ecologia e Recursos Naturais) - UFSCAR, São Carlos, SP, 2003. 


\section{Gestãoe \\ Desenvolvimento}

e-ISSN: 2446-6875

p-ISSN: $1807-5436$

TRICAUD, S.; PINTON, F.; PEREIRA, H. dos S. Saberes e práticas locais dos produtores de guaraná. Bol. Mus. Para. Emílio Goeldi, Belém, v. 11, n. 1, p. 33-53, jan./abr., 2016.

VIEGAS, C. V. Atividades de gestão do conhecimento na elaboração do estudo de impacto ambiental. 2009. 362 f. Tese (Doutorado em Engenharia e Gestão do Conhecimento) - UFSC, Florianópolis, SC, 2009.

WANDERLEY, M. de N. B. O agricultor familiar no Brasil: um ator social da construção do futuro. In: PETERSEN, Paulo (org.). Agricultura familiar camponesa na construção do futuro. Rio de Janeiro: As-pta, p. 33-45, 2009.

WANDERLEY, M. de N. B. A valorização da agricultura familiar e a reivindicação da ruralidade no Brasil. Desenvolvimento e Meio ambiente, Curitiba, n. 2, p. 29-37, 2000.

WESZ JUNIOR, V. J.; TRENTIN, I. C. L. Agregação de Valor e Desenvolvimento Sustentável nos Municípios Rurais. Gestão e desenvolvimento, Novo Hamburgo, v. 3, n. 2, jul./dez. 2006.

ZUCHIWSCHI, E.; FANTINI, A. C.; ALVES, A. C.; PERONI, N. Limitações ao uso de espécies florestais nativas pode contribuir com a erosão do conhecimento ecológico tradicional e local de agricultores familiares.

Acta Bot. Bras., v. 24, n. 1, p. 270-282, 2016. 